\title{
Racial/ethnic disparities among Asian Americans in inpatient acute myocardial infarction mortality in the United States
}

Eun Ji Kim", Nancy R. Kressin ${ }^{2,3}$, Michael K. Paasche-Orlow², Lenny Lopez ${ }^{4}$, Jennifer E. Rosen ${ }^{5}$, Mengyun Lin ${ }^{2}$ and Amresh D. Hanchate ${ }^{2,3}$

\begin{abstract}
Background: Acute myocardial infarction (AMI) is a common high-risk disease with inpatient mortality of 5\% nationally. But little is known about this outcome among Asian Americans (Asians), a fast growing racial/ethnic minority in the country. The objectives of the study are to obtain near-national estimates of differences in AMl inpatient mortality between minorities (including Asians) and non-Hispanic Whites and identify comorbidities and sociodemographic characteristics associated with these differences.
\end{abstract}

Method: This is a retrospective analysis of 2010-2011 state inpatient discharge data from 10 states with the largest share of Asian population. We identified hospitalization with a primary diagnosis of AMI using the ICD-9 code and used self-reported race/ethnicity to identify White, Black, Hispanic, and Asian. We performed descriptive analysis of sociodemographic characteristics, medical comorbidities, type of AMI, and receipt of cardiac procedures. Next, we examined overall inpatient AMI mortality rate based on patients' race/ethnicity. We also examined the types of AMI and a receipt of invasive cardiac procedures by race/ethnicity. Lastly, we used sequential multivariate logistic regression models to study inpatient mortality for each minority group compared to Whites, adjusting for covariates.

Results: Over $70 \%$ of the national Asian population resides in the 10 states. There were 496,472 hospitalizations with a primary diagnosis of AMl; $75 \%$ of all cases were Whites, $10 \%$ were Blacks, $12 \%$ were Hispanics, and $3 \%$ were Asians. Asians had a higher prevalence of cardiac comorbidities, including hypertension, diabetes, and kidney failure compared to Whites ( $p$-value< 0.01). There were 158,623 STEMI (ST-elevation AMI), and the proportion of hospitalizations for STEMI was the highest for Asians (35.2\% for Asians, 32.7\% for Whites, 25.3\% for Blacks, and 32.1\% for Hispanics). Asians had the highest rates of inpatient AMI mortality: 7.2\% for Asians, 6.3\% for Whites, 5.4\% for Blacks, and 5.9\% for Hispanics (ANOVA p-value < 0.01). In adjusted analyses, Asians (OR=1.11 [95\% Cl: 1.04-1.19]) and Hispanics (OR=1.14 [1.09-1.19]) had a higher likelihood of inpatient mortality compared to Whites.

Conclusions: Asians had a higher risk-adjusted likelihood of inpatient AMl mortality compared to Whites. Further research is needed to identify the underlying reasons for this finding to improve AMI disparities for Asians.

Keywords: Acute myocardial infarction, Mortality, comorbidities, Health disparity, Asian

\footnotetext{
* Correspondence: ekim7@northwell.edu

${ }^{1}$ General Internal Medicine, Zucker School of Medicine at Hofstra/Northwell,

2001 Marcus Avenue Suite S160, Lake Success, NY 11042, USA

Full list of author information is available at the end of the article
}

(c) The Author(s). 2018 Open Access This article is distributed under the terms of the Creative Commons Attribution 4.0 International License (http://creativecommons.org/licenses/by/4.0/), which permits unrestricted use, distribution, and reproduction in any medium, provided you give appropriate credit to the original author(s) and the source, provide a link to the Creative Commons license, and indicate if changes were made. The Creative Commons Public Domain Dedication waiver (http://creativecommons.org/publicdomain/zero/1.0/) applies to the data made available in this article, unless otherwise stated. 


\section{Background}

Coronary artery disease is a common condition that affects 15 million adults in the US and about 715,000 people have acute myocardial infarction (AMI) annually [1]. AMI mortality has been significantly reduced with advances in care, standardization of AMI management, and modifications of AMI-related risk factors [2-4]. Despite these improvements, there exist significant racial and ethnic disparities in the treatment and outcome of AMI [5-21]. These studies have shown that minorities, mostly non-Hispanic Blacks and Hispanics, are less likely to have cardiac invasive procedures and have higher AMI mortality compared to non-Hispanic Whites. However, little is known about inpatient AMI mortality of Asians residing in the US due to limited numbers of national data that identify Asians (e.g. the National Health and Nutrition Examination Survey only started to identify Asians starting 2011).

Asian Americans (henceforth referred to as Asians), including Pacific Islanders, make up $4.8 \%$ of the US population and the population has been growing faster than the national rate [22]. Overall, Asians in the population have a relatively low prevalence of AMI-related comorbidities, including obesity, diabetes, smoking, and hypertension [23-26] and a relatively low national AMI mortality rate (age-adjusted AMI mortality rate from death certificate for non-Hispanic White men was 196.7/ 100,000 population and Asian men was 109.1/100,000 population in 1998) [27]. Despite studies that have examined health disparities involving Asians for other medical conditions such as stroke [28, 29], previous research looking at racial/ethnic disparities in AMI outcomes is limited. Many AMI studies have focused on non-Asian minorities in the US or involved Asians residing in Asian countries [29-32]. These studies showed mixed results, ranging from no differences to significant differences in outcomes.

To address the gaps in the literature on differences in AMI outcomes among Asian Americans and to provide updates in national AMI outcomes, we investigated the following research questions using comprehensive data from 10 states that together account for over $70 \%$ of the national Asian American (Asian) population: [1] Are there differences in observed AMI inpatient mortality between each of the minority groups (Asians, Blacks, or Hispanics) and Whites? [2] What is the riskadjusted inpatient AMI mortality of minorities compared to Whites? [3] What are the sociodemographic and clinical characteristics associated with inpatient AMI mortality? By answering these questions, we want to understand racial/ethnic differences in inpatient AMI mortality as well as identify characteristics that are associated with differences in AMI inpatient mortality.

\section{Methods}

\section{Study population}

Our primary data was the 2010-2011 state inpatient discharge data, containing all patient discharges at nonfederal short-term acute hospitals, from 10 US states California, Florida, Illinois, Massachusetts, Maryland, New Jersey, New York, Pennsylvania, Texas, and Virginia. These states were selected based on having sizable Asian populations and the completeness of race/ethnicity reporting in the discharge data. Data for California, Texas, Illinois, Pennsylvania, Massachusetts, and Virginia were obtained from the respective state agencies [33], and data for remaining states were obtained from AHRQ HCUP Central Distributor [34]. The data was built and designed after the Feng et al. paper [35]. The selected 10 states contained $70 \%$ of the national Asian population (Appendix 1). We identified all discharges for adult patients aged 18 and older with the principal diagnosis of AMI (ICD-9: 410) [36]. We excluded 64,561 patients who were transferred to another shortterm hospital, admitted with obstetric-related conditions, and missing key variables (discharge disposition, gender, age, discharge quarter/year, principal diagnosis, or admission information) [37].

\section{Race/ethnicity}

We used self-reported race/ethnicity and categorized patients into the following race/ethnicity groups: Hispanics, (non-Hispanic) Whites, (non-Hispanic) Blacks, (non-Hispanic) Asians, Others or unknown (i.e., missing). For the subjects with missing race/ethnicity information (2.6\% of the study population), race/ethnicity was reassigned using the "hot-deck" statistical imputation method [38]. This method randomly assigns race/ethnicity for patients with missing race/ethnicity in the same proportion as the race/ethnicity distribution for those with known race/ethnicity. As previous studies have indicated that Others include a sizable proportion of Whites, we grouped Others with Whites in all the analyses [39].

\section{Covariates}

Based on previous studies, we identified key demographics, comorbidities, types of AMI, and use of invasive cardiac procedures that were associated with AMI mortality. Socio-demographic variables included sex, age, and state of residence [17, 40-44]. We categorized age into seven groups: $18-34,35-44,45-54$, 55-64, 65-74, 75-84, and 85+. We used Elixhauser categories to identify comorbidities and determined whether the patient had the comorbid condition or not (comorbid conditions include congestive heart failure, cardiac arrhythmias, valvular disease, pulmonary circulation disorders, peripheral vascular disease, 
hypertension, paralysis, other neurological disorders, chronic pulmonary disease, diabetes (uncomplicated), diabetes with chronic complications, hypothyroidism, renal failure, liver disease, peptic ulcer disease without bleeding, acquired immune deficiency syndrome, lymphoma, metastatic cancer, solid tumor without metastasis, rheumatoid arthritis/collagen vascular diseases, coagulopathy, obesity, weight loss, fluid and electrolyte disorders, blood loss anemia, deficiency anemias, alcohol abuse, drug abuse, psychoses, depression) [45]. Using secondary diagnosis codes reported in the index discharge records, the Elixhauser method identifies 30 risk groups associated with inpatient mortality; these are defined as 30 separate indicator $(0 / 1)$ fields. For types of AMI, we differentiated AMI cases into non-ST-segment elevation (NSTEMI) (ICD-9 $=410.7)$ and ST-segment elevation MI (STEMI) (all ICD-9 $=410$ excluding 410.7). We used diagnosis and procedure codes from the International Classification of Diseases, Ninth Revision, Clinical modification and corresponding Current Procedural Terminology to code for the invasive cardiac procedures of coronary artery bypass surgery (CABG) and percutaneous coronary intervention (PCI) [36].

\section{Primary outcome: Inpatient acute MI mortality}

The main outcome was inpatient mortality from a hospitalization for AMI (ICD-9: 410). This is one of the Inpatient Quality Indicators measured by the Agency for Healthcare Research and Quality (AHRQ) [37].

\section{Statistical analysis}

Statistical analysis was conducted using SAS software, version 9.3 (SAS Institute Inc., Cary, NC). We performed descriptive analysis of socio-demographic characteristics, medical comorbidities, and types of AMI based on patients' race/ethnicity. We performed chisquare and t-tests to compare differences between each of the minority groups and Whites. Next, we examined use of PCI and CABG for overall AMI, and then among those with STEMI and NSTEMI.

We used multivariable logistic regression models to study differences in inpatient mortality among racial/ ethnic minorities (Asians, Hispanics, and Blacks) compared to Whites. To better identify the source of differences in inpatient mortality, we estimated odds ratios in a sequence of models, adjusting for a wider array of covariates in the following order: age, gender, geographical location (state), co-morbidities (Elixhauser categories), type of AMI, and invasive cardiac procedures (CABG and PCI). We did not correct for multiple testing. Sensitivity analyses were performed to examine disparities in AMI mortality among those who were transferred from another short-term hospital, since this subgroup of patients may be systematically different in severity.

The Boston University Institutional Review Board approved this study.

\section{Results}

We identified 561,041 AMI cases. Of these, we excluded 62,267 (11.1\%) AMI admissions that were transferred to another hospital as we do not have information regarding their health outcomes (percentages of each racial/ethnic groups excluded: Asians = $14.5 \%$, White $=10.9 \%$, Black $=11.3 \%$, and Hispanics $=$ $11.3 \%)$. In addition, we excluded 2302 (0.4\%) AMI cases with obstetric-related conditions or missing key variables. The study sample included 496,472 AMI cases.

\section{Socio-demographic characteristics}

Table 1 shows the characteristics of the total sample as well as subgroups of the different racial/ethnic groups. The majority of the study population were White (75\%), followed by $12 \%$ Hispanics, $10 \%$ Black, and $3 \%$ Asian. There was a significant difference in mean age and percentages of women in different racial/ethnic groups (ANOVA; $p$-value $<0.01$ for both). Mean average age was the oldest for White (mean age $=69.4$ years old) and the youngest for Black (mean age $=63.8$ years old). Significantly higher percentage of Black patients (48.0\%) and lower percentage of Asian patients (35.2\%) were women compared to Whites $(39.4 \%)(p$-values< 0.05$)$. There were wide variations in racial/ethnic composition in each of the 10 states.

\section{Clinical characteristics}

We examined the prevalence of each of the comorbidities in the Elixhauser comorbidity index (Table 2). Compared to Whites, Asians had a mixed profile of comorbid conditions, with lower prevalence of some conditions (obesity, cardiac arrhythmia, and peripheral vascular disease), but higher prevalence of a wider range of conditions (congestive heart failure, diabetes, hypertension, renal failure, and coagulopathy) (all $p$-values were less than 0.01). There were significant racial/ethnic differences in the average length of stay and number of Elixhauser comorbidity diagnoses (ANOVA; both $p$-value $<0.01$ ). Among different groups, each of the minority groups had longer average length of stay and Blacks had the highest average number of diagnoses (11.6 diagnoses) compared to Whites (Table 3).

Next, we differentiated type of AMI; there were 337,849 (68.0\%) hospitalizations for NSTEMI and 
Table 1 Socio-demographic characteristics of AMI hospitalizations by race/ethnicity ${ }^{\text {** }}$

\begin{tabular}{|c|c|c|c|c|c|}
\hline Variable & All $(n=496,472)$ & Asian $(n=14,977)$ & White $(n=372,556)$ & Black $(n=51,403)$ & Hispanic $(n=57,536)$ \\
\hline \multicolumn{6}{|l|}{ Age } \\
\hline Mean age, years old (SD) & $68.3(14.7)$ & $67.2(14.5)$ & $69.4(14.5)$ & $63.8(14.6)^{*}$ & $65.3(14.4)^{*}$ \\
\hline \multicolumn{6}{|l|}{ Age groups (\%) } \\
\hline $18-34$ & 0.8 & 1.0 & 0.6 & 1.7 & 1.4 \\
\hline $35-44$ & 4.3 & 5.1 & 3.7 & 6.9 & 5.9 \\
\hline $45-54$ & 14.3 & 14.6 & 13.2 & 19.8 & 17.0 \\
\hline $55-64$ & 22.0 & 22.9 & 21.1 & 25.1 & 24.5 \\
\hline $65-74$ & 21.4 & 22.2 & 21.2 & 21.1 & 22.2 \\
\hline $75-84$ & 21.3 & 20.9 & 22.4 & 16.4 & 19.0 \\
\hline $85+$ & 15.9 & 13.3 & 17.9 & 9.0 & 10.0 \\
\hline \multicolumn{6}{|l|}{ Gender } \\
\hline Women (\%) & 40.0 & $35.2^{*}$ & 39.4 & $48.0^{*}$ & 37.7 \\
\hline \multicolumn{6}{|l|}{ State of residence ${ }^{* *}(\%)$} \\
\hline California & $n=92,285$ & 9.6 & 63.6 & 7.2 & 19.6 \\
\hline Florida & $n=78,753$ & 0.7 & 75.8 & 9.4 & 14.1 \\
\hline Illinois & $n=39,950$ & 2.0 & 78.1 & 14.1 & 5.8 \\
\hline Massachusetts & $n=23,176$ & 1.7 & 90.2 & 4.0 & 4.0 \\
\hline Maryland & $n=15,523$ & 1.9 & 72.5 & 24.0 & 1.6 \\
\hline New Jersey & $n=29,662$ & 3.0 & 76.8 & 11.3 & 8.8 \\
\hline New York & $n=59,521$ & 2.7 & 78.9 & 10.7 & 7.8 \\
\hline Pennsylvania & $n=57,160$ & 0.5 & 89.8 & 7.8 & 2.0 \\
\hline Texas & $n=74,553$ & 1.3 & 66.3 & 10.9 & 21.6 \\
\hline Virginia & $n=25,889$ & 1.6 & 67.6 & 18.3 & 1.5 \\
\hline
\end{tabular}

${ }^{a}$ Values are means (standard deviation) or percentages of patients

${ }^{*}$ P-value $<0.05$ when each of the racial/ethnic group (Asian, White, or Black) was compared to White

**Racial/ethnic distribution in each state

Table 2 Prevalence of co-morbidities (Elixhauser comorbidities) by race/ethnicity

\begin{tabular}{|c|c|c|c|c|}
\hline Variable & $\begin{array}{l}\text { Asian } \\
(n=14,977)\end{array}$ & $\begin{array}{l}\text { White } \\
(n=372,556)\end{array}$ & $\begin{array}{l}\text { Black } \\
(n=51,403)\end{array}$ & $\begin{array}{l}\text { Hispanic } \\
(n=57,536)\end{array}$ \\
\hline \multicolumn{5}{|c|}{$\%$ of AMI hospitalizations with the comorbidities } \\
\hline Congestive heart failure & 34.5 & 31.9 & 35.5 & $32.0^{*}$ \\
\hline Cardiac arrhythmias & 36.5 & 39.5 & 31.8 & 31.3 \\
\hline Peripheral vascular disease & 9.4 & 11.3 & $11.2^{*}$ & 10.6 \\
\hline Hypertension & 75.7 & 70.5 & 82.4 & 75.9 \\
\hline Chronic pulmonary disease & 13.6 & 20.5 & 18.5 & 14.9 \\
\hline Diabetes, uncomplicated & 33.6 & 26.4 & 34.1 & 38.8 \\
\hline Diabetes with chronic complications & 11.7 & 5.7 & 9.0 & 10.3 \\
\hline Renal failure & 26.6 & 18.3 & 28.1 & 22.0 \\
\hline Coagulopathy & 7.4 & 5.0 & $4.9^{*}$ & $5.2^{*}$ \\
\hline Deficiency anemias & 23.1 & 15.4 & 21.8 & 19.4 \\
\hline
\end{tabular}

${ }^{*} P$-value $\geq 0.05$ when each of the racial/ethnic group (Asian, White, or Black) was compared to White (unmarked signify $p$-value $<0.05$ ) 
Table 3 Clinical characteristics of AMl hospitalizations by race/ethnicity ${ }^{a}$

\begin{tabular}{|c|c|c|c|c|}
\hline Variable & Asian & White & Black & Hispanic \\
\hline Number of diagnoses (SD) & $11.3(6.2)$ & $11.3(5.2)$ & $11.6(5.2)^{*}$ & $10.8(5.2)^{*}$ \\
\hline Length of stay, days (SD) & $6.2(7.4)^{*}$ & $5.3(17.4)$ & $5.6(7.0)^{*}$ & $5.9(19.5)^{*}$ \\
\hline \multicolumn{5}{|l|}{ Types of AMl } \\
\hline STEMI & $35.2^{*}$ & 32.7 & $25.3^{*}$ & $32.1^{*}$ \\
\hline NSTEMI & $64.8^{*}$ & 67.3 & $74.7^{*}$ & $67.9^{*}$ \\
\hline \multicolumn{5}{|c|}{ Receipt of invasive cardiac procedures } \\
\hline $\mathrm{PCl}$ & 48.0 & 48.2 & $41.0^{*}$ & $47.6^{*}$ \\
\hline CABG & $10.6^{*}$ & 9.3 & $6.5^{*}$ & $10.2^{*}$ \\
\hline \multicolumn{5}{|c|}{ Receipt of invasive cardiac procedures by AMI type } \\
\hline \multicolumn{5}{|l|}{ STEMI $(n=158,623)$} \\
\hline $\mathrm{PCl}$ & 69.5 & 72.1 & $68.1^{*}$ & 72.2 \\
\hline CABG & $8.0^{*}$ & 7.3 & $5.4^{*}$ & $8.1^{*}$ \\
\hline \multicolumn{5}{|l|}{ NSTEMI $(n=337,849)$} \\
\hline $\mathrm{PCl}$ & 36.3 & 36.5 & $31.9^{*}$ & $35.9^{*}$ \\
\hline CABG & $12.0^{*}$ & 10.2 & $6.9^{*}$ & $11.3^{*}$ \\
\hline
\end{tabular}

${ }^{a}$ Values are means (standard deviation) or percentages of patients

${ }^{*} P$-value $<0.05$ when each of the racial/ethnic group (Asian, White, or Black) was compared to White

158,623 (32.0\%) hospitalizations for STEMI (Table 3). Significantly higher proportion of Asians (35.2\%) had STEMI and lower proportions of Blacks (25.3\%) or Hispanics $(32.1 \%)$ had STEMI compared to Whites $(32.7 \%)$ ( $p$-values $<0.05)$. We also examined the prevalence of cardiac procedure use, specifically percutaneous coronary intervention (PCI) and coronary artery bypass graft (CABG). Among AMI hospitalization by Asians, $48.0 \%$ received PCI and $10.6 \%$ received CABG; this is similar for PCI and higher for CABG compared to Whites. Regardless of type of procedure or AMI, Blacks had the lowest rate of cardiac procedures during the hospitalization. In regards to mortality after cardiac procedures (PCI or CABG), Asians had higher mortality compared to non-Asians $(p<0.01)$, specifically after PCI (Appendix 2).

\section{Observed inpatient AMI mortality}

There were significant differences in observed inpatient AMI mortality among different racial and ethnic groups. Asians had the highest observed inpatient AMI mortality (inpatient mortality Asian= 7.2\%; White $=6.3 \%$; Black $=5.4 \%$, and Hispanic $=5.9 \%$ ). This finding persisted for both STEMI (inpatient mortality Asian $=10.4 \%$; White $=9.4 \%$; Black $=9.8 \%$, and Hispanic $=8.8 \%$ ) and NSTEMI (inpatient mortality Asian $=5.4 \%$; White $=4.8 \%$; Black $=3.9 \%$, and Hispanic $=4.6 \%$ ).

Table 4 Odds ratio [95\% confidence interval] of inpatient AMI mortality associated with race/ethnicity (reference: non-Hispanic White)

\begin{tabular}{|c|c|c|c|}
\hline & $\begin{array}{l}\text { Asian } \\
(n=14,977)\end{array}$ & $\begin{array}{l}\text { Black } \\
(n=51,403)\end{array}$ & $\begin{array}{l}\text { Hispanic } \\
(n=57,536)\end{array}$ \\
\hline Model 1: Unadjusted & $1.16[1.09-1.23]$ & $0.85[0.81-0.88]$ & $0.94[0.91-0.97]$ \\
\hline Model 2: Model 1+ Age group & $1.27[1.19-1.35]$ & $1.06[1.02-1.11]$ & $1.11[1.07-1.15]$ \\
\hline Model 3: Model 2+ Gender & $1.27[1.19-1.35]$ & $1.06[1.02-1.11]$ & $1.11[1.07-1.15]$ \\
\hline Model 4: Model 3+ Geography (state) & $1.21[1.14-1.30]$ & $1.05[1.00-1.09]$ & $1.09[1.05-1.13]$ \\
\hline Model 5: Model 4+ Patient comorbidities (Elixhauser grouping) & $1.13[1.06-1.21]$ & $1.04[1.00-1.09]$ & $1.15[1.10-1.19]$ \\
\hline Model 6: Model 5+ Type of AMl & $1.12[1.04-1.20]$ & $1.12[1.07-1.17]$ & $1.17[1.12-1.22]$ \\
\hline Model 7: Model 6+ Receipt of PTCA or CABG & $1.11[1.04-1.19]$ & $1.02[0.98-1.06]$ & $1.14[1.09-1.19]$ \\
\hline
\end{tabular}


Models of inpatient AMI mortality adjusting for covariates We examined the racial/ethnic differences in AMI mortality using a sequence of multivariable logistic models, cumulatively including covariates from the different domains (Table 4). Model 1 (which only included race/ethnicity variable) reported higher unadjusted AMI mortality among Asians (odds ratio $(\mathrm{OR})=1.16$ [95\% CI: 1.09-1.23]) compared to Whites; in contrast, Blacks (OR $=0.85[0.81-0.88])$ and Hispanics $(\mathrm{OR}=0.94$ [0.91-0.97] $)$ had lower mortality. After adjusting for age differences (model 2), all minority groups (Asian $\mathrm{OR}=1.27$ [95\% CI: 1.19-1.35], Black OR = 1.06 [95\% CI: 1.02-1.11], and Hispanic OR $=1.11$ [95\% CI: 1.07-1.15]) had higher mortality compared to Whites. This trend persisted even after adjusting for gender, state of residence, and comorbidities; however, the Asian versus White gap decreased after accounting for differences in comorbidities (Model 5). When type of AMI was included in the analysis (Model 6), likelihood of AMI mortality increased and became significant for Blacks compared to Whites. In the final model (Model 7), there was a shift in AMI mortality among Blacks (from $\mathrm{OR}=1.12$ [1.07-1.17] to OR $=1.02$ [95\% CI: 0.98-1.06]) when invasive cardiac procedures were included in the model. Including the cardiac procedure covariate did not change the significance of AMI mortality of either Asians $(\mathrm{OR}=1.11$ [1.04-1.19]) or Hispanics $(\mathrm{OR}=1.14$ [1.09-1.19]) when compared to Whites. Sensitivity analysis looking at the subgroup of AMI hospitalizations of patients transferred from another short-term hospital $(n=81,888)$ showed no significant difference in inpatient AMI mortality between minorities and White (Asian $\mathrm{OR}=0.86 \quad[0.68-1.08] ;$ Black $\mathrm{OR}=0.94 \quad[0.82-1.08]$; and Hispanic OR $=1.02$ [0.89-1.16]) after adjusting for covariates.

\section{Discussion}

Using comprehensive AMI discharge data from 10 states that contains $70 \%$ of the U.S. population of Asians, we found that Asians had the highest observed inpatient AMI mortality. There were differences in sociodemographic and clinical characteristics among different racial/ethnic groups. In risk-adjusted inpatient mortality, the extent of the mortality differences was reduced after adjusting for comorbidities, an indication of higher prevalence of comorbidities among Asians admitted with AMI. In the final model adjusting for sociodemographic characteristics, comorbidities, type of AMI, and invasive cardiac procedure use, Asians and Hispanics remained to have increased likelihoods of inpatient mortality compared to Whites.

One plausible explanation for the higher AMI inpatient mortality among Asians is higher disease burden and severity, specifically among those with elevated risk of AMI. As noted, there was a sizable reduction in the AMI mortality among Asians after adjusting for observed comorbidities, which indicates higher overall comorbidity burden. This pattern of higher comorbidity risk among Asian AMI hospitalizations contrasts with epidemiologic evidence of lower disease burden among the general population of Asians [23-26]. The population level death rate from AMI is lower among Asians, compared to Whites [27]; this is not inconsistent with our finding of higher mortality among hospitalizations for AMI, since our study does not take into account the risk of being hospitalized (for AMI). The higher cardiovascular risk among some Asians may partly be explained by their recent adoption of western diet and habits in the U.S. as well as worldwide [46, 47]. The shift in cardiovascular risk factors are associated with acculturation, particularly the number of years residing in the US [48-50]. Given no significant differences in likelihoods of AMI mortality among those who were transferred from another short-term hospital, disparities are not due to racial/ethnic differences in the proportion of patients who were transferred across hospitals. Instead, disparities were concentrated largely among cases where patients were treated in the hospitals where they were initially admitted.

Besides comorbidities, we observed higher AMI inpatient mortality among Asians who had cardiac procedures. We do not have information regarding decisions behind why patients received cardiac procedures but the high cardiac procedure rate among Asians might be due to more advanced or severe cases that require invasive interventions. The higher mortality among those receiving cardiac procedures needs further examination, as identifying contributing factors can improve future outcomes. If the high mortality is due to a high comorbidity burden, future studies should focus on restratifying risk for all AMI patients. However, if the high mortality is coming from procedure-related complications common among Asians, such as high bleeding risk after anti-platelet therapy [51-53], then different medical therapies, such as lower doses of antithrombotic medications, should be used. The absence of data about complications is a limitation of our study, thus we could not examine this further. Also, Asians with AMI may seek medical care when cardiac symptoms are severe and have been present for longer durations. Delays in receiving care have been associated with poor outcomes [54-56]. In a study that examined AMI patients experiencing symptoms for less than $24 \mathrm{~h}$, there was no difference in mortality between Asians and Whites [32]. Our study did not differentiate patients based on their duration of symptoms, and the high mortality could have originated from higher inpatient mortality among Asians with longer duration of symptoms. 
Another explanation is that certain Asian subgroups are contributing more to the high inpatient AMI mortality. Asians encompass diverse population and studies have identified heterogeneity in cardiovascular disease risk factors among Asians by country of origin. For example, previous studies have identified that South Asians have more cardiovascular risk factors and worse outcomes compared to Whites [57-59]. In addition, another study found that certain Asian and Hispanic ethnic groups have significantly lower insurance rates [60] and it is possible that these small groups of Asians with disadvantageous socioeconomic factors may experience a significantly greater impact on AMI mortality due to limited healthcare access and decreased preventive care visits. Lastly, the presence of language barriers among Asians with limited English proficiency could contribute to poor health outcomes [61, 62], and possibly higher AMI mortality.

There are several limitations of this retrospective observational study. Given our observational data, a causal relationship cannot be established between being Asian and increased inpatient AMI mortality. Due to the nature of secondary, administrative data, information on clinical patient status is limited. For example, clinical information regarding duration or severity of symptoms, admission vitals, EKG findings, and procedure complications could have provided further insight. The data also did not include medications, which would have been helpful in understanding race/ethnicity-specific medical management of AMI, or how clinical decisions were made in obtaining invasive cardiac procedures. Previous research has shown mixed results as to whether racial differences existed in decision-making involving invasive cardiac procedures $[14,63]$. We are missing data in some states on other covariates such as health insurance status, educational achievement, and household income, which could affect patients' access and decision to seek medical care for AMI. Our data also does not contain acculturation information, which could indirectly provide immigrants' newly adopted cardiovascular risks. The findings may not be generalizable to states with small Asian populations, since we only included 10 states with a sizeable Asian population. Lastly, there has been a significant increase in multiracial populations, especially Asians tied to other races or ethnicities [22]. For our study, we used selfreported race/ethnicity, which did not identify multiracial patients.

\section{Conclusion}

These data are among the first to show that Asian patients hospitalized with acute myocardial infarction had higher observed AMI mortality than Black, Hispanic, or White patients. The findings may have been driven by higher disease severity, heterogeneous riskassociated with Asian subgroups, and delayed medical care. We observed higher inpatient AMI mortality among Asians compared to Whites even after adjusting for sociodemographic and clinical characteristics. With the increasing number of Asians in the US, disparities in AMI mortality will become more significant. Further research should focus on patient-level details to better understand the heterogeneity of the Asian population and clinical factors associated with such disparities.

\section{Appendix 1}

Table 5 2010-2011 Census population and crude state-level counts of AMI by race/ethnicity (Age 18+)

\begin{tabular}{|c|c|c|c|c|c|c|c|c|c|c|}
\hline \multirow[b]{2}{*}{ State } & \multicolumn{5}{|c|}{ Crude state-level counts of AMI } & \multicolumn{5}{|c|}{ State share (\%) of national census population of adults, 2010} \\
\hline & $\overline{\text { Asian }}$ & White & Black & Hispanics & All & $\overline{\text { Asian }}$ & White & Black & Hispanics & All \\
\hline California & 8815 & 58,703 & 6673 & 18,094 & 92,285 & $33.1 \%$ & $7.9 \%$ & $6.1 \%$ & $27.8 \%$ & $11.9 \%$ \\
\hline New York & 1610 & 46,953 & 6338 & 4620 & 59,521 & $9.7 \%$ & $5.8 \%$ & $8.2 \%$ & $7.3 \%$ & $6.4 \%$ \\
\hline Texas & 949 & 49,415 & 8105 & 16,084 & 74,553 & $6.6 \%$ & $5.8 \%$ & $7.6 \%$ & $18.4 \%$ & $7.8 \%$ \\
\hline New Jersey & 899 & 22,792 & 3359 & 2612 & 29,662 & $4.9 \%$ & $2.6 \%$ & $3.1 \%$ & $3.3 \%$ & $2.9 \%$ \\
\hline Illinois & 784 & 31,217 & 5648 & 2301 & 39,950 & $4.0 \%$ & $4.1 \%$ & $4.8 \%$ & $3.9 \%$ & $4.1 \%$ \\
\hline Florida & 522 & 59,677 & 7423 & 11,131 & 78,753 & $3.1 \%$ & $5.8 \%$ & $7.6 \%$ & $9.4 \%$ & $6.3 \%$ \\
\hline Virginia & 425 & 20,340 & 4744 & 380 & 25,889 & $3.0 \%$ & $2.6 \%$ & $4.1 \%$ & $1.3 \%$ & $2.6 \%$ \\
\hline Massachusetts & 398 & 20,912 & 936 & 930 & 23,176 & $2.4 \%$ & $2.6 \%$ & $1.1 \%$ & $1.2 \%$ & $2.2 \%$ \\
\hline Maryland & 295 & 11,248 & 3731 & 249 & 15,523 & $2.2 \%$ & $1.6 \%$ & $4.5 \%$ & $1.0 \%$ & $1.9 \%$ \\
\hline Pennsylvania & 280 & 51,299 & 4446 & 1135 & 57,160 & $2.4 \%$ & $5.2 \%$ & $3.5 \%$ & $1.4 \%$ & $4.2 \%$ \\
\hline Total & 14,977 & 372,556 & 51,403 & 57,536 & 496,472 & $76.0 \%$ & $50.4 \%$ & $52.6 \%$ & $84.6 \%$ & $56.8 \%$ \\
\hline
\end{tabular}




\section{Appendix 2}

Table 6 Percentage of patients receiving invasive cardiac procedure treatment for $\mathrm{AMI}$ and their observed inpatient mortality

\begin{tabular}{ccllll}
\hline Variable & Asian & White & Black & Hispanic & $P$-value* \\
\hline \multicolumn{2}{l}{ AMI $(n=496,472)$} & & & & \\
PCl or CABG & $57.6 \%$ & $56.5 \%$ & $47.0 \%$ & $56.8 \%$ & $<0.01$ \\
Mortality & $3.7 \%$ & $3.1 \%$ & $2.9 \%$ & $3.4 \%$ & $<0.01$ \\
PCI & $48.0 \%$ & $48.2 \%$ & $41.0 \%$ & $47.6 \%$ & 0.09 \\
Mortality & $3.6 \%$ & $3.0 \%$ & $2.7 \%$ & $3.4 \%$ & 0.01 \\
CABG & $10.6 \%$ & $9.3 \%$ & $6.5 \%$ & $10.2 \%$ & $<0.01$ \\
Mortality & $4.6 \%$ & $3.9 \%$ & $4.6 \%$ & $3.4 \%$ & 0.15 \\
\hline
\end{tabular}

*Comparing Asians versus non-Asians (combined non-Hispanic White, non-Hispanic Black, and Hispanic)

\begin{abstract}
Abbreviations
AHRQ: Agency for Healthcare Research and Quality; AMI: Acute myocardial infarction; ANOVA: Analysis of variance; Asian: Asian American;

CABG: Coronary artery bypass graft; CPT: Current procedural terminology; ICD: International Classification of Disease; NSTEMI: Non-ST-segment elevation myocardial infarction; OR: Odds ratio; PCl: Percutaneous coronary intervention; STEMI: ST-segment elevation myocardial infarction
\end{abstract}

\section{Acknowledgements}

Joint Acknowledgment/Disclosure Statement: The authors acknowledge the support of their home institutions, Boston University School of Medical, Boston Medical Center, Boston VA, MedStar Washington Hospital Center, and the University of California at San Francisco, for providing work space and infrastructure to facilitate the completion of this work.

The views expressed in this article are those of the authors and do not necessarily represent the views of the National Institutes of Health, Hofstra Northwell School of Medicine, Boston University, MedSTAR Washington Hospital Center, Harvard Medical School, or Department of Veterans Affairs.

\section{Funding}

This research has been partially supported by NIH grant 1R01MD007705 (A. Hanchate, PI). This funding supported the design of the study and the collection, analysis and interpretation of the data. Dr. Kim was funded by a training grant from the VA Office of Academic Affiliations and supported by the National Center for Advancing Translational Sciences, National Institutes of Health, through BU-CTSI Grant 1UL1TR001430. Dr. Kressin is supported in part by a Veterans Affairs Health Services Research and Development Senior Research Career Scientist Award (RCS 02-066). Dr. Lenny López acknowledges the support of the Robert Wood Johnson Foundation Harold Amos Medical Faculty Development Program and NIDDK 1K23DK098280-01.

\section{Availability of data and materials}

We acknowledge the following agencies for providing state data: Pennsylvania Health Care Cost Containment Council (PHC4), Illinois Department of Public Health, Office of Policy Planning and Statistics, Massachusetts Center for Health Information and Analysis, Texas Healthcare Information Collection, New York State Department of Health Statewide Planning and Research Cooperative System, and Virginia Department of Health. All analyses are our own, and the agencies bear no responsibility or liability for the results. The datasets generated and/or analyzed for this study are available from the listed agencies, but restrictions apply to the availability of these data, which were used under license for the current study, and so are not publicly available.

\section{Authors' contributions}

EK and $\mathrm{AH}$ participated in the design of the study. EK and ML performed the statistical analysis. NK, MP, LL, and JR have made substantial contributions to conception and design of the study and have discussed and interpreted the study results extensively. All authors revised the manuscript and have read and approved its final version.

\section{Ethics approval and consent to participate}

This study was approved by the Institutional Review Board at Boston University and a waiver of consent was granted.

\section{Competing interests}

The authors declare that they have no competing interests.

\section{Publisher's Note}

Springer Nature remains neutral with regard to jurisdictional claims in published maps and institutional affiliations.

\begin{abstract}
Author details
${ }^{1}$ General Internal Medicine, Zucker School of Medicine at Hofstra/Northwell, 2001 Marcus Avenue Suite S160, Lake Success, NY 11042, USA. General Internal Medicine, Boston University School of Medicine, 801 Massachusetts Avenue, Crosstown Two, Boston, MA 02118, USA. ${ }^{3}$ VA Boston Healthcare System, 150 S. Huntington Avenue, Boston, MA 02130, USA. ${ }^{4}$ University of California San Francisco School of Medicine, 4150 Clement Street, San Francisco, CA 94121, USA. ${ }^{5}$ MedStar Washington Hospital Center, 106 Irving Street NW POB South 124, Washington, DC 20010, USA.
\end{abstract}

Received: 29 August 2017 Accepted: 2 May 2018

Published online: 16 May 2018

\section{References}

1. Roger VL, Go AS, Lloyd-Jones DM, et al. Executive summary: heart disease and stroke statistics-2012 update: a report from the American Heart Association. Circulation. 2012:125(1):188-97.

2. Yeh RW, Sidney S, Chandra M, Sorel M, Selby JV, Go AS. Population trends in the incidence and outcomes of acute myocardial infarction. N Engl J Med. 2010;362(23):2155-65.

3. Rogers WJ, Canto JG, Lambrew CT, et al. Temporal trends in the treatment of over 1.5 million patients with myocardial infarction in the US from 1990 through 1999: the National Registry of myocardial infarction 1, 2 and 3. J Am Coll Cardiol. 2000;36(7):2056-63.

4. Ford ES, Ajani UA, Croft JB, et al. Explaining the decrease in U.S. deaths from coronary disease, 1980-2000. N Engl J Med. 2007:356(23):2388-98.

5. Schneider EC, Leape LL, Weissman JS, Piana RN, Gatsonis C, Epstein AM. Racial differences in cardiac revascularization rates: does "overuse" explain higher rates among white patients? Ann Intern Med. 2001;135(5):328-37.

6. Conigliaro J, Whittle J, Good CB, et al. Understanding racial variation in the use of coronary revascularization procedures: the role of clinical factors. Arch Intern Med. 2000;160(9):1329-35.

7. Hannan EL, van Ryn M, Burke J, et al. Access to coronary artery bypass surgery by race/ethnicity and gender among patients who are appropriate for surgery. Med Care. 1999;37(1):68-77.

8. Ford E, Cooper R, Castaner A, Simmons B, Mar M. Coronary arteriography and coronary bypass survey among whites and other racial groups relative to hospital-based incidence rates for coronary artery disease: findings from NHDS. Am J Public Health. 1989:79(4):437-40.

9. Johnson PA, Lee TH, Cook EF, Rouan GW, Goldman L. Effect of race on the presentation and management of patients with acute chest pain. Ann Intern Med. 1993;118(8):593-601.

10. Peterson ED, Shaw LK, DeLong ER, Pryor DB, Califf RM, Mark DB. Racial variation in the use of coronary-revascularization procedures. Are the differences real? Do they matter. N Engl J Med. 1997;336(7):480-6.

11. Giles WH, Anda RF, Casper ML, Escobedo LG, Race THA. Sex differences in rates of invasive cardiac procedures in US hospitals. Data from the National Hospital Discharge Survey. Arch Intern Med. 1995;155(3):318-24.

12. Franks AL, May DS, Wenger NK, Blount SB, Eaker ED. Racial differences in the use of invasive coronary procedures after acute myocardial infarction in Medicare beneficiaries. Ethnicity \& disease. 1993;3(3):213-220. 
13. Ayanian JZ, Udvarhelyi IS, Gatsonis CA, Pashos CL, Epstein AM. Racia differences in the use of revascularization procedures after coronary angiography. JAMA. 1993;269(20):2642-6.

14. Carlisle DM, Leake BD, Shapiro MF. Racial and ethnic disparities in the use of cardiovascular procedures: associations with type of health insurance. Am J Public Health. 1997:87(2):263-7.

15. Whittle J, Conigliaro J, Good CB, Lofgren RP. Racial differences in the use of invasive cardiovascular procedures in the Department of Veterans Affairs medical system. N Engl J Med. 1993;329(9):621-7.

16. Maynard C, Fisher LD, Passamani ER, Pullum T. Blacks in the coronary artery surgery study (CASS): race and clinical decision making. Am J Public Health. 1986;76(12):1446-8.

17. Jneid H, Fonarow GC, Cannon CP, et al. Sex differences in medical care and early death after acute myocardial infarction. Circulation. 2008;118(25):2803-10.

18. Wenneker MB, Epstein AM. Racial inequalities in the use of procedures for patients with ischemic heart disease in Massachusetts. JAMA. 1989;261(2):253-7.

19. Kressin NR, Petersen LA. Racial differences in the use of invasive cardiovascular procedures: review of the literature and prescription for future research. Ann Intern Med. 2001;135(5):352-66.

20. Barnato AE, Lucas FL, Staiger D, Wennberg DE, Chandra A. Hospital-level racial disparities in acute myocardial infarction treatment and outcomes. Med Care. 2005;43(4):308-19.

21. Vaccarino V, Rathore SS, Wenger NK, et al. Sex and racial differences in the management of acute myocardial infarction, 1994 through 2002. N Engl J Med. 2005;353(7):671-82

22. Hoeffel EM, Rastogi, S., Kim, M.O., Hasan S. The Asian population: 2010. 2012

23. Ogden CL, Carroll MD, Kit BK, Flegal KM. Prevalence of childhood and adult obesity in the United States, 2011-2012. JAMA. 2014;311(8):806-14.

24. Mensah GA, Mokdad AH, Ford ES, Greenlund KJ, Croft JB. State of disparities in cardiovascular health in the United States. Circulation. 2005;111(10):1233-41.

25. Agaku IT, King BA, Dube SR. Centers for disease C, prevention. Current cigarette smoking among adults - United States, 2005-2012. MMWR Morb Mortal Wkly Rep. 2014;63(2):29-34.

26. Prevention. CfDCa. National diabetes fact sheet: national estimates and general information on diabetes and prediabetes in the United States, 2011. Atlanta, GA: US Department of Health and Human Services, Centers for Disease Control and Prevention.;2011.

27. Centers for Disease. C, prevention. Mortality from coronary heart disease and acute myocardial infarction-United States, 1998. MMWR Morb Mortal Wkly Rep. 2001;50(6):90-3.

28. Bhandari VK, Kushel M, Price L, Schillinger D. Racial disparities in outcomes of inpatient stroke rehabilitation. Arch Phys Med Rehabil. 2005;86(11):2081-6.

29. Christian JB, Lapane KL, Toppa RS. Racial disparities in receipt of secondary stroke prevention agents among US nursing home residents. Stroke. 2003;34(11):2693-7.

30. Gadegbeku C, Freeman M, Agodoa L. Racial disparities in renal replacement therapy. J Natl Med Assoc. 2002;94(8 Suppl):45S-54S.

31. de Carvalho LP, Gao F, Chen Q, et al. Differences in late cardiovascular mortality following acute myocardial infarction in three major Asian ethnic groups. Eur Heart J Acute Cardiovasc Care. 2014;3(4):354-62.

32. Wang TY, Chen AY, Roe MT, et al. Comparison of baseline characteristics, treatment patterns, and in-hospital outcomes of Asian versus non-Asian white Americans with non-ST-segment elevation acute coronary syndromes from the CRUSADE quality improvement initiative. Am J Cardiol. 2007;100(3):391-6.

33. Agency for Healthcare Research and Quality. State Inpatient Databases. Agency for Healthcare Research \& Quality:2015e.

34. Agency for Healthcare Research and Quality. HCUP Partners. https://www. hcup-us.ahrq.gov/partners.jsp: Agency for Healthcare Research \& Quality; 2015c. [accessed on May 15, 2015].

35. Feng C, Paasche-Orlow MK, Kressin NR, et al. Disparities in potentially preventable hospitalizations: near-National Estimates for Hispanics. Health Serv Res. 2017;

36. International Classification of Diseases, Ninth Revision. Clinical Modification. US Dept of Health and Human Services: Public Health Service; 1988.

37. $\mathrm{AHRQ} \mathrm{Q}$ I Research version 5.0. Inpatient quality indicator 15 technical specifications: acute myocardial infarction (AMI) mortality rate. US Department of Health and Human Services, Agency for Healthcare Research and Quality; 2015.
38. Coffey RM, Barrett M, Houchens E, et al. "Methods Applying AHRQ Quality Indicators to Heathcare Cost and Utilization Project (HCUP) Data for the Tenth (2012) National Healthcare Quality Report (NHQR) and National Healthcare Disparities Report (NHDR).". 2012

39. McBean AM, Gornick M. Differences by race in the rates of procedures performed in hospitals for Medicare beneficiaries. Health Care Financ Rev. 1994;15(4):77-90.

40. Khera S, Kolte D, Gupta T, et al. Temporal trends and sex differences in revascularization and outcomes of ST-segment elevation myocardial infarction in younger adults in the United States. J Am Coll Cardiol. 2015;66(18):1961-72.

41. Ayanian JZ, Epstein AM. Differences in the use of procedures between women and men hospitalized for coronary heart disease. N Engl J Med. 1991;325(4):221-5.

42. Rathore SS, Berger AK, Weinfurt KP, et al. Race, sex, poverty, and the medical treatment of acute myocardial infarction in the elderly. Circulation. 2000;102(6):642-8

43. Lloyd-Jones DM, Larson MG, Beiser A, Levy D. Lifetime risk of developing coronary heart disease. Lancet. 1999;353(9147):89-92.

44. Kolte D, Khera S, Aronow WS, et al. Regional variation across the United States in management and outcomes of ST-elevation myocardial infarction: analysis of the 2003 to 2010 nationwide inpatient sample database. Clin Cardiol. 2014;37(4):204-12.

45. Elixhauser A, Steiner C, Harris DR, Coffey RM. Comorbidity measures for use with administrative data. Med Care. 1998;36(1):8-27.

46. Danaei G, Finucane MM, Lu Y, et al. National, regional, and global trends in fasting plasma glucose and diabetes prevalence since 1980: systematic analysis of health examination surveys and epidemiological studies with 370 country-years and 2.7 million participants. Lancet. 2011;378(9785):31-40.

47. Ng M, Fleming $T$, Robinson $M$, et al. Global, regional, and national prevalence of overweight and obesity in children and adults during 19802013: a systematic analysis for the global burden of disease study 2013. Lancet. 2014;384(9945):766-81.

48. Chiu M, Austin PC, Manuel DG, Tu JV. Cardiovascular risk factor profiles of recent immigrants vs long-term residents of Ontario: a multi-ethnic study. Can J Cardiol. 2012;28(1):20-6.

49. Kandula NR, Diez-Roux AV, Chan C, et al. Association of acculturation levels and prevalence of diabetes in the multi-ethnic study of atherosclerosis (MESA). Diabetes Care. 2008;31(8):1621-8.

50. Stern MP. Honolulu heart study: review of epidemiologic data and design. Prog Clin Biol Res. 1984;147:93-104.

51. Mehta RH, Parsons L, Peterson ED. National registry of myocardial infarction I. Comparison of bleeding and in-hospital mortality in Asian-Americans versus Caucasian-Americans with ST-elevation myocardial infarction receiving reperfusion therapy. Am J Cardiol. 2012;109(7):925-31.

52. Ueshima S, Matsuo O. The differences in thrombolytic effects of administrated recombinant t-PA between Japanese and Caucasians. Thromb Haemost. 2002;87(3):544-6

53. Ethnicity and cardiovascular disease. The incidence of myocardial infarction in white, south Asian, and afro-Caribbean patients with type 2 diabetes (U.K. prospective diabetes study 32). Diabetes Care. 1998;21(8):1271-7.

54. De Luca G, Suryapranata H, Ottervanger JP, Antman EM. Time delay to treatment and mortality in primary angioplasty for acute myocardial infarction: every minute of delay counts. Circulation. 2004;109(10):1223-5.

55. Newby LK, Rutsch WR, Califf RM, et al. Time from symptom onset to treatment and outcomes after thrombolytic therapy. GUSTO-1 investigators. J Am Coll Cardiol. 1996;27(7):1646-55.

56. De Luca G, Suryapranata H, Zijlstra F, et al. Symptom-onset-to-balloon time and mortality in patients with acute myocardial infarction treated by primary angioplasty. J Am Coll Cardiol. 2003;42(6):991-7.

57. Wilkinson P, Sayer J, Laji K, et al. Comparison of case fatality in south Asian and white patients after acute myocardial infarction: observational study. BMJ. 1996:312(7042):1330-3.

58. Chiu M, Maclagan LC, Tu JV, Shah BR. Temporal trends in cardiovascular disease risk factors among white, south Asian, Chinese and black groups in Ontario, Canada, 2001 to 2012: a population-based study. BMJ Open. 2015;5(8):e007232

59. Gasevic D, Khan NA, Qian H, et al. Outcomes following percutaneous coronary intervention and coronary artery bypass grafting surgery in Chinese, south Asian and white patients with acute myocardial infarction: administrative data analysis. BMC Cardiovasc Disord. 2013;13:121. 
60. Alegria M, Cao Z, McGuire TG, et al. Health insurance coverage for vulnerable populations: contrasting Asian Americans and Latinos in the United States. Inquiry. 2006:43(3):231-54.

61. Sentell T, Braun KL. Low health literacy, limited English proficiency, and health status in Asians, Latinos, and other racial/ethnic groups in California. J Health Commun. 2012;17(Suppl 3):82-99.

62. Sentell T, Braun KL, Davis J, Davis T. Colorectal cancer screening: low health literacy and limited English proficiency among Asians and whites in California. J Health Commun. 2013;18(Suppl 1):242-55.

63. Gordon HS, Paterniti DA, Wray NP. Race and patient refusal of invasive cardiac procedures. J Gen Intern Med. 2004;19(9):962-6.

Ready to submit your research? Choose BMC and benefit from:

- fast, convenient online submission

- thorough peer review by experienced researchers in your field

- rapid publication on acceptance

- support for research data, including large and complex data types

- gold Open Access which fosters wider collaboration and increased citations

- maximum visibility for your research: over $100 \mathrm{M}$ website views per year

At BMC, research is always in progress.

Learn more biomedcentral.com/submissions 